\title{
Dr. Abdul Jaleel V. ( 1970-2019)
}

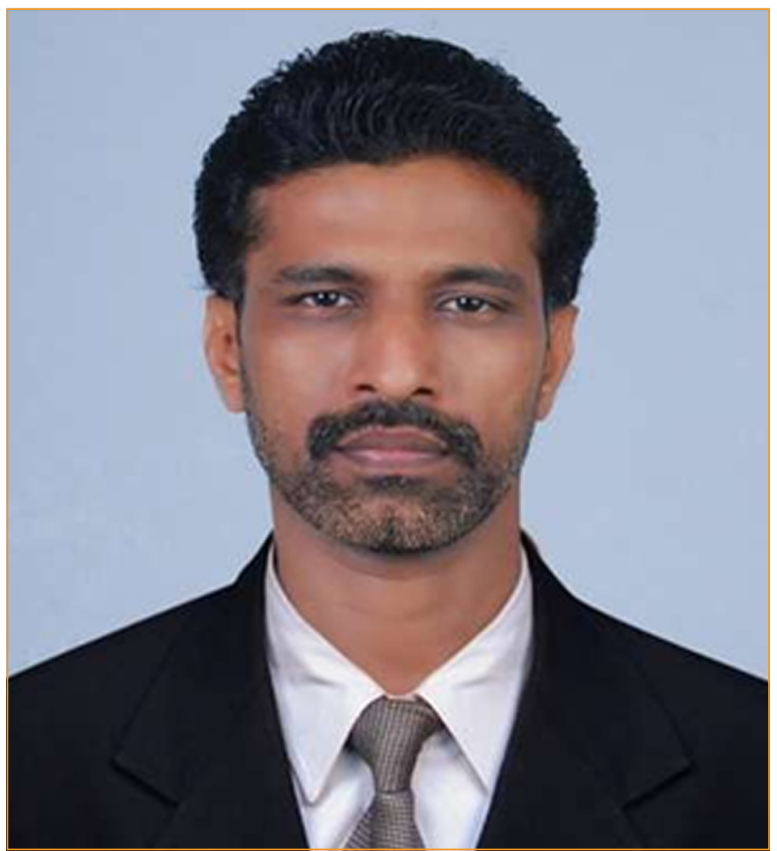

Dr. Abdul Jaleel, V. passed away in the early hours of $10^{\text {th }}$ August, 2019 at his residence in Mahe. He was 49 , and survived by his wife and three children. With his untimely sad and sudden demise the Indian Botany lost an outstanding taxonomist of International repute. Dr. Abdul Jaleel will be greatly remembered for his remarkable contributions that enriched plant taxonomy, phytogeography and conservation biology in India through his dedicated research of nearly two decades.

Dr. Abdul Jaleel was born on 20.10.1970 in Azhiyur, Mahe. He had his primary and secondary school education at his home town and later joined the Mahatma Gandhi Arts and Science College, Mahe under Puducherry State to pursue his Bachelor degree in Science (B.Sc.). Later he obtained his B.Ed., M.Sc., and M.Phil. degrees from the Pondicherry Central University. Further he pursued his studies at the Annamalai University for M.Ed. Degree. He worked at the University of Calicut, Kerala under the supervision of Prof. M.
Sivadasan, Former Head, Department of Botany, University of Calicut for his Ph.D. degree. He was a bright student who secured high scores in all his courses.

His career in Botany began as a Teacher at the Markaz Higher Secondary School, Karanthur, Kunnamangalam, Kozhikode district. Dr. Abdul Jaleel joined as an Assistant Professor of Botany at the Department of Botany, Sir Syed College, Taliparamba, Kannur in the year 2010. Since 2018 he was the Head of the Department. He was member of PG Board of Studies, Calicut University, and UG Board of studies, Kannur University and various other professional bodies. As a Life Member of the Indian Association for Angiosperm Taxonomy (IAAT) and the Centre for Research in Indigenous Knowledge, Science \& Culture (CRIKSC), he was active throughout his life.

Dr. Abdul Jaleel was recipient of several honours and awards including the prestigious Dr. K.S. Manilal Young Scientist Award of the IAAT for the best papers in floristics consecutively in 1999 and 2000 at the Annual Conferences of IAAT held at Calicut, Kerala and West Bengal respectively. He also received Dr. R.S. Rao Young Scientist Award for the best paper in Biodiversity Conservation presented at the National Seminar in Plant Taxonomy and Biodiversity conservation held during 20-31 December 2004 at Thiruvananthapuram, Kerala. Dr. Jaleel was a recipient of Dr. M. Sabu Award of IAAT for Teachers for the best paper in Angiosperm taxonomy presented at the International seminar on Taxonomy, Plant Diversity and Conservation held during 26-28 November, 2010 at Bharathiar University, Coimbatore, Tamil Nadu. He won the Best Paper Presentation Award-2014 for his paper presented at the Asian Plant Science Conference held during 1-3 November, 2014 at Nepal. Apart 
from the above he has presented papers in various National and International seminars.

Dr. Jaleel had successfully completed four Research Projects funded by various agencies like UGC, Kerala State Higher Education Council, Kerala State Biodiversity Board and the Kerala State Medicinal Plants Board.

Dr. Abdul Jaleel has 36 research articles to his credit published in National and International Journals. Also, he has contributed to Indian taxonomy by publishing several new taxa.

New species and varieties:

1. Amorphophallus bognerianus Sivad. \& Jaleel (Araceae)

2. Lagenandra keralensis Sivad. \& Jaleel (Araceae)

3. Lindernia nelliyampathiensis Sunil, Jaleel \& Ratheesh (Scrophulariaceae)

4. Rotala khaleeliana Sunil, Ratheesh \& Nandakumar (Lythraceae)

5. Eriocaulon vandaanamense Sunil, Ratheesh \& Sivad. (Eriocaulaceae)

6. Fimbristylis pokkudaniana Sunil, Ratheesh \& Sivad. (Cyperaceae)

7. Amorphophallus commutatus var. wynadensis Sivad. \& Jaleel (Araceae)

8. Amorphophallus commutatus var. anmodensis Sivad. \& Jaleel (Araceae)
9. Amorphophallus mysorensis var. bhandarensis (S.R.Yadav, Kahalkar \& Bhuskute) Sivad. \& Jaleel (Araceae)

Dr. Jaleel was a Research Guide of Kannur University, and four research scholars were working under his guidance.

He has constructed an Aroid Home at the Botanical Garden of the Sir Syed College and introduced several rare aroids from various parts of India.

In Addition to his taxonomic research work, he spent more time in social activities. He was the NSS programme officer of the college and won the Best NSS Unit and Programme Officer Award of the Kannur University during the year 2017.

He was a hard working and brilliant taxonomist especially in the area of Indian Aroids. His other passions included photography and social works. He was also very fond of travelling and had visited many parts of India and country like Nepal for his research purpose. We will greatly miss his dynamic presence and guidance, but hope his academic and social activities would influence and inspire us to continue his rich legacy of lifelong learning, and promotion and popularization of science.

Abdul Salam Sir Syed College, Taliparamaba 